\title{
Identification of white campion (Silene latifolia) guaiacol O-methyltransferase involved in the biosynthesis of veratrole, a key volatile for pollinator attraction
}

\author{
Alok K. Gupta ${ }^{1,2^{*}}$, Tariq A. Akhtar ${ }^{3}$, Alex Widmer ${ }^{2}$, Eran Pichersky ${ }^{3}$ and Florian P. Schiestl ${ }^{1}$
}

\begin{abstract}
Background: Silene latifolia and its pollinator, the noctuid moth Hadena bicruris, represent an open nursery pollination system wherein floral volatiles, especially veratrole (1, 2-dimethoxybenzene), lilac aldehydes, and phenylacetaldehyde are of key importance for floral signaling. Despite the important role of floral scent in ensuring reproductive success in S. latifolia, the molecular basis of scent biosynthesis in this species has not yet been investigated.

Results: We isolated two full-length cDNAs from S. latifolia that show similarity to rose orcinol O-methyltransferase. Biochemical analysis showed that both S. latifolia guaiacol O-methyltransferasel (SIGOMT1) \& S. latifolia guaiacol O-methyltransferase2 (SIGOMT2) encode proteins that catalyze the methylation of guaiacol to form veratrole. A large $\mathrm{K}_{\mathrm{m}}$ value difference between SIGOMT1 $(\sim 10 \mu \mathrm{M})$ and SIGOMT2 $(\sim 501 \mu \mathrm{M})$ resulted that SIGOMT1 is 31-fold more catalytically efficient than SIGOMT2. qRT-PCR expression analysis showed that the SIGOMT genes are specifically expressed in flowers and male S. latifolia flowers had 3- to 4-folds higher level of GOMT gene transcripts than female flower tissues. Two related cDNAs, S. dioica O-methyltransferase1 (SdOMT1) and S. dioica O-methyltransferase2 (SdOMT2), were also obtained from the sister species Silene dioica, but the proteins they encode did not methylate guaiacol, consistent with the lack of veratrole emission in the flowers of this species. Our evolutionary analysis uncovered that SIGOMT1 and SIGOMT2 genes evolved under positive selection, whereas SdOMT1 and SdOMT2 genes show no evidence for selection.
\end{abstract}

Conclusions: Altogether, we report the identification and functional characterization of the gene, S/GOMT1 that efficiently catalyzes veratrole formation, whereas another copy of this gene with only one amino acid difference, SIGOMT2 was found to be less efficient for veratrole synthesis in S. latifolia.

Keywords: Floral scent, VOC, 1, 2-dimethoxybenzene, Pollination, Hadena bicruris

\section{Background}

White campion, Silene latifolia (Caryophyllaceae), emits a diverse array of volatiles to attract sphingid, geometrid, and noctuid moths for pollination [1-4]. This species also shows a pronounced day-night rhythm in odor emission, with the key compounds predominately emitted during

\footnotetext{
* Correspondence: alok.gupta@systbot.uzh.ch; ethalok@yahoo.com 'Institute of Systematic Botany, University of Zurich, Zurich CH-8008, Switzerland

${ }^{2}$ ETH Zurich, Institute of Integrative Biology, Plant Ecological Genetics, Zurich CH-8092, Switzerland

Full list of author information is available at the end of the article
}

the night [4-7]. Among commonly known pollinators for this species, Hadena bicruris, a noctuid moth, is a specialist nursery pollinator and obligate seed predator $[8,9]$. Female $H$. bicruris are not only attracted for nectaring but also for oviposition into female $S$. latifolia flowers [10]. The larvae nurture on developing seeds [11] and consume almost one fourth of the fruits developed $[12,13]$. Available experimental evidence indicates that the Hadena-Silene relationship can swing in between mutualism and antagonism [9]. 
Recently, the scent composition of S. latifolia and related species has been identified and studied for behavioral activity in the pollinators $[4,10,14]$. A large set of volatile compounds has been found in the S. latifolia floral odor bouquet $[6,7,13,15]$ and these compounds comprise three major categories: fatty acid derivatives, aromatics, and terpenoids [6,7]. Using wind-tunnel bioassays, Dötterl et al. [13] investigated pollinators interaction with individual scent compound and uncovered that only seven (veratrole, decanal, linalool, guaiacol, phenylacetaldehyde, isopentylaldoxime, and lilac aldehydes) out of total produced compounds in S. latifolia flowers showed behavioral activity in $H$. bicruris. A further study based on scent composition analysis revealed that veratrole and lilac aldehydes emission is reduced four-folds after pollination, while other behaviorally active and non-active compounds remain unaltered [10]. Therefore, apart from being involved in pollinator attraction, the decrease in veratrole and lilac aldehyde emission may slow down oviposition and subsequent seed predation by Hadena following pollination. Phenylacetaldehyde, one of the most abundant behaviorally active compounds, is involved in floral isolation of $S$. latifolia from the closely related species $S$. dioica [6]. These investigations altogether imply that veratrole, lilac aldehydes, and phenylacetaldehyde are key odor compounds that play a central role in pollinator attraction and floral isolation $[6,7,10,14]$. It is presently unclear which compounds induce oviposition by Hadena females into female $S$. latifolia flowers. $H$. bicruris rarely oviposits into $S$. dioica [11]. However, the qualitative difference in floral volatile organic compounds (VOCs) between S. dioica and S. latifolia involves only few compounds. Veratrole, guaiacol, and benzyl benzoate are produced only in S. latifolia but a fatty acid derivative, nonanal is only emitted by $S$. dioica [6]. Therefore, besides quantitative scent differences [6], three compounds produced in S. latifolia are involved in species differentiation and presumably in maintaining the Hadena-Silene latifolia relationship.

During the past two decades, molecular research on Silene has primarily focused on sex-determination [16-19], the evolution of heteromorphic sex chromosomes [20-24], hybridization [25,26], and EST sequencing for species differentiation or marker development $[27,28]$. The production of copious amounts of behaviorally active volatile compounds also makes Silene an ideal system for investigating genes underlying volatile biosynthesis. At present, though, scent biosynthetic pathways remain uncharacterized in Silene. Among several scent enzymes known so far, the plant $\mathrm{O}$-methyltransferase (OMT) family of enzymes performs a prominent role in secondary metabolism and eliminates a methyl group from S-adenosyl-L-methionine to the hydroxyl group of the substrate [29]. Besides playing a role in lignin biosynthesis [30,31], anthocyanin biosynthesis [32,33], and disease resistance [34-36], these OMTs are also involved in volatile biosynthesis [37-40]. For instance, eugenol $O$-methyltransferase (EOMT) and chavicol $\mathrm{O}$-methyltransferase (CVOMT) methylate the substrates in order to synthesize methyleugenol and methylchavicol, respectively [41,42]. Studies in roses reported the functional characterization of orcinol O-methyltransferases (OOMT1 and OOMT2) genes that are involved in the formation of 3-hydroxy 5-methoxytoluene and 3,5-dimethoxytoluene (DMT), two key scent compounds of rose varieties [43,44]. Until now, several plant methyltransferases have been functionally characterized owing to their involvement in floral scent biosynthesis and flavoring properties $[42,45,46]$.

As part of an ongoing research project to characterize key genes involved in floral scent biosynthesis in Silene species, we have recently developed a S. latifolia floral EST resource of 3,072 sequences by constructing one standard and two subtraction cDNA libraries (Gupta et al. in prep). The analysis of these sequences allowed us to characterize a wide range of candidate genes including several OMTs with high similarities to functionally characterized OMTs in other species. Here we show that two full-length coding cDNAs derived from these libraries represent S. latifolia guaiacol O-methyltransferase1 (SlGOMT1) and S. latifolia guaiacol O-methyltransferase2 (SlGOMT2) genes and address the following questions: 1) Do heterologously expressed proteins catalyze the formation of veratrole in S. latifolia and S. dioica? 2) How do differences in veratrole emission between day and night in S. latifolia controlled? 3) Are SlGOMT genes differentially expressed between floral and leaf tissues, and between sexes? 4) Do SlGOMT and S. dioica O-methyltransferase $(S d O M T)$ genes show evidence for selection?

\section{Results \\ Isolation and characterization of GOMT and GOMT-like cDNAs}

A search of the EST database constructed from S. latifolia flowers (Gupta et al. in prep) for sequences homologous to known O-methyltransferases identified ESTs, and the sequence information in these ESTs led to the isolation of two coding cDNA sequences of 1,059 bp that we designated as SIGOMT1 and SIGOMT2. These sequences encode peptide sequences of 353 amino acids and the molecular mass of both purified SIGOMT proteins was approximately $37 \mathrm{kD}$ on SDS-PAGE, similar to other plant-based methyltransferases [29] (Figures 1\&2). SIGOMT1 and SIGOMT2 were nearly identical with the exception of two nucleotides differences that result in one amino acid difference at position 74 . This weak divergence suggests that the two sequences correspond to different alleles of the same locus. An alignment of 


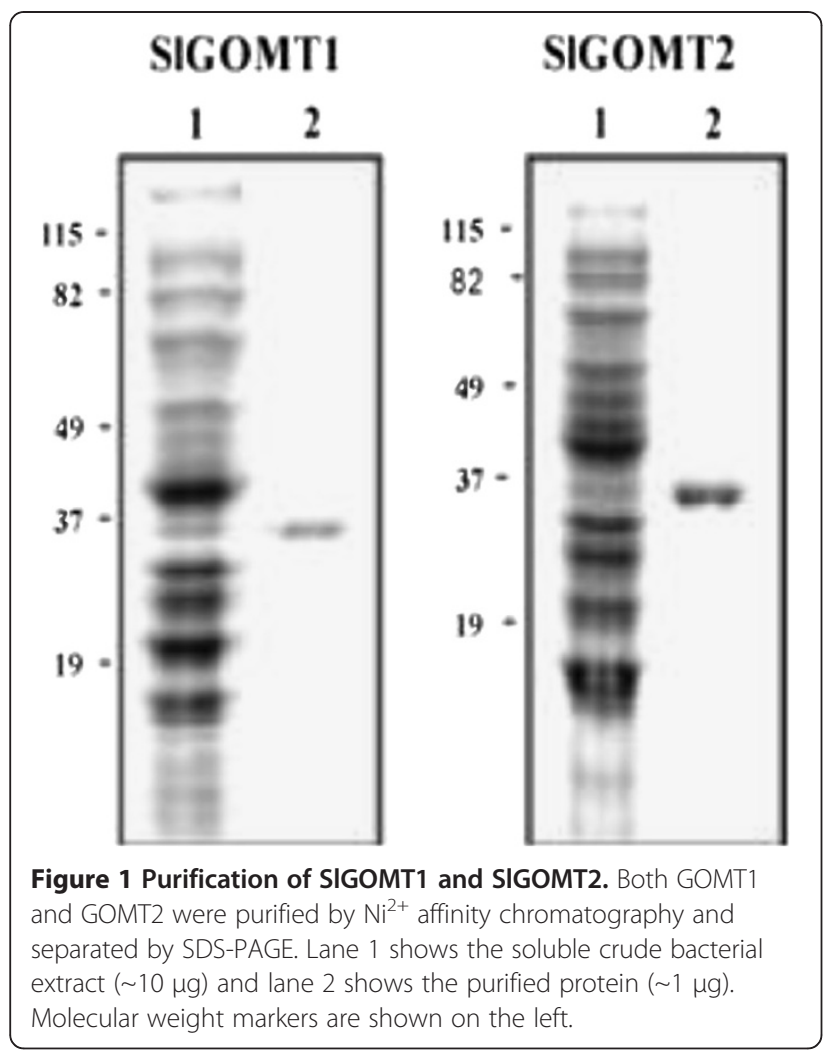

the deduced SIGOMT1 and SIGOMT2 protein sequences with other characterized protein sequences is shown in Figure 2. The comparison of deduced amino acid sequences between SlGOMTs (SlGOMT1 and SlGOMT2) and biochemically characterized OMTs of other plants revealed the 54-55\% identity with orcinol OMTs from Rosa hybrida [43] and 54\% identity with resveratrol OMT from Vitis [35]. Further Blast searches also showed 45\% identity with Ocimum eugenol OMT [42] and 31\% identity with Solanum catechol OMT [47]. Based on primers designated for SlGOMT1 and SlGOMT2, we were also able to obtain two GOMT-like coding cDNAs of 1,062 bp long from RNA extracted from $S$. dioica flowers and we designated them SdOMT1 and SdOMT2. These both sequences shared $89-90 \%$ identity with SlGOMT1 and SIGOMT2.

\section{Biochemical characterization of SIGOMTs and SdOMTs}

SIGOMTs and SdOMTs were expressed in E. coli and the proteins tested for methylation activity with guaiacol, the presumed substrate of veratrole, as well as orcinol, the substrate of OOMT, eugenol, the substrate of EOMT, and catechol, a compound recently shown to be the substrate of a methyltransferase in tomato, which converts it to guaiacol [47]. Methyleugenol, which has no hydroxyl groups that could be methylated, was used as a control (Table 1). SlGOMT1 exhibited preferred activity with guaiacol and was efficiently able to methylate guaiacol to veratrole (Figures 3, 4, 5 \& Additional file 1: Figure S4), with a $K_{m}$ value for guaiacol of $9.8 \mu \mathrm{M}$ (Table 2). SIGOMT2 had low levels of activity with several substrates, including guaiacol (Table 1) and a $\mathrm{K}_{\mathrm{m}}$ value for guaiacol, $501 \mu \mathrm{M}$, that is 51 -fold higher than that of SIGOMT1 (Table 2), resulting an enzyme that is 31-fold less efficient with guaiacol than SIGOMT1 (Table 2). SdOMT1 and SdOMT2 did not methylate any of these tested substrates.

\section{Veratrole emission}

Veratrole emission from both female and male flowers was 50-77 orders of magnitude higher during the night than during the day $(\mathrm{Z}=-3.321, p=0.001$; Table 3$)$. As expected, there was no veratrole emission detected from leaf tissue, indicating that veratrole is a flower-specific compound (leaf volatile data is not shown in Table 3). However, there was no significant difference in veratrole emission for male and female flowers $(\mathrm{Z}=0, p=1)$.

\section{Gene expression analysis}

To ascertain whether SlGOMT genes are differentially expressed between flowers and leaves in S. latifolia, qRT-PCR analyses were performed (Table 3). Our results show that SlGOMT genes are preferentially expressed in floral tissue, whereas no expression was detected in leaf tissues (Table 3, data is not shown for leaf tissue in this table). Surprisingly, there was no significant difference found in SlGOMT gene expression in flowers collected during day and night $(\mathrm{Z}=-0.680, p=0.529)$. However, SlGOMT expression is significantly (3-4 folds) higher in males than in females during day and night $(\mathrm{Z}=-3.250, p=0.001)$.

\section{Evolutionary analysis}

To analyze evolutionary relationships and patterns of sequence evolution in SlGOMTs and SdOMTs sequences, we retrieved a total of 92 plant OMT sequences from NCBI (Additional file 2: Table S1) following the criteria described in the methods section. These sequences were combined with our SlGOMTs and SdOMTs sequences to construct a Bayesian inference phylogeny. All identified Silene sequences formed a separate clade and showed distant relationships with $M$. truncatula isoflavone7-Omethyltransferase (IOMT) gene. A maximum likelihoodbased analysis of synonymous versus non-synonymous mutations was performed to test for the signature of selection. Our analysis revealed strong evidence for positive selection $(\omega=2.38 ; p=0.0017)$ along the branch leading to SlGOMT1 and SlGOMT2, whereas no evidence for positive selection was found along the branch to SdOMT1 and SdOMT2 (Additional file 3: Table S2). Purifying selection was found along the branch linking the SlGOMT and SdOMT sequences $(\omega=0.14$; $p=0.0032$; Figure 6). 


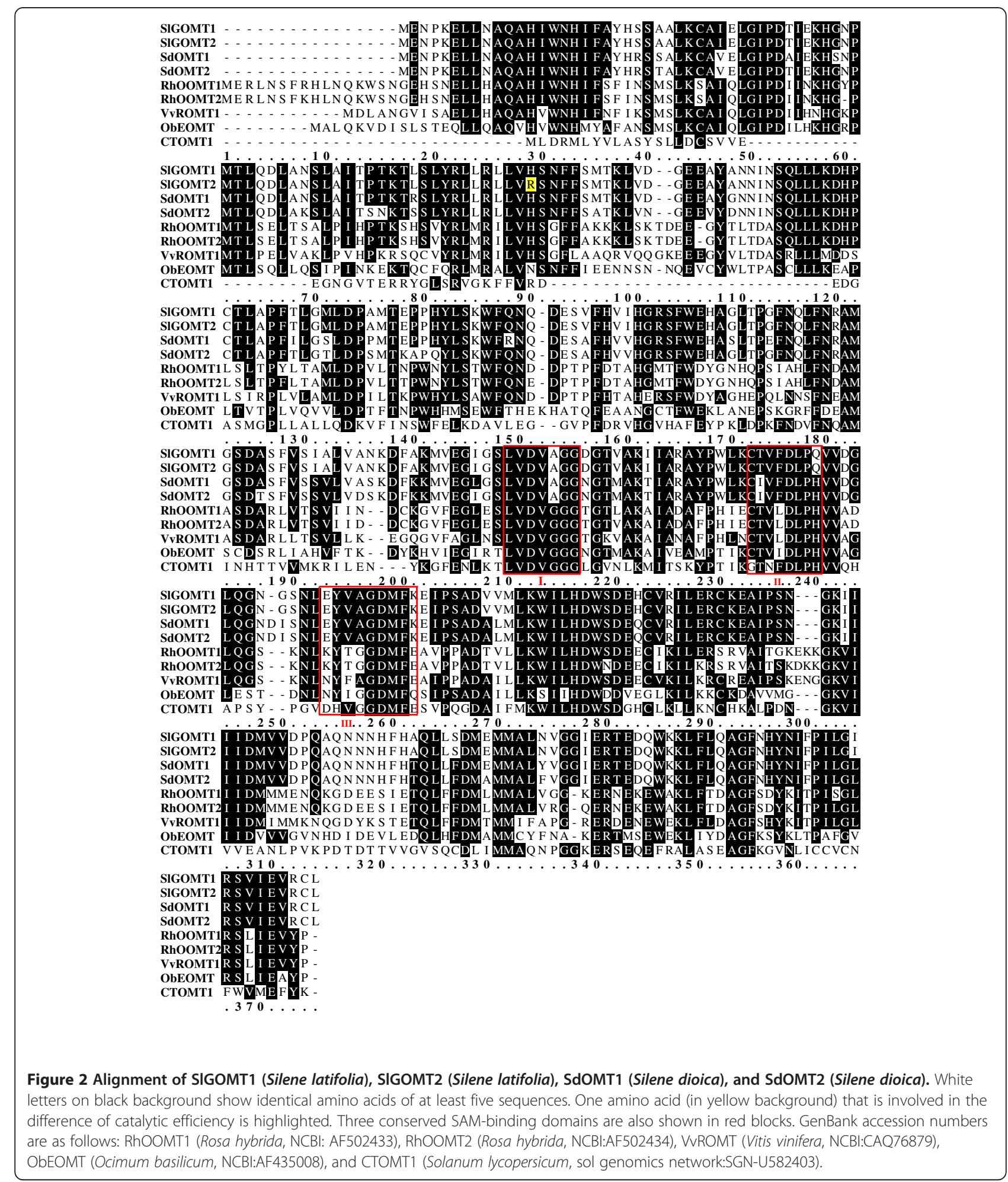

\section{Discussion}

In this paper, we report the identification of a novel enzyme that is responsible for the formation of veratrole (1, 2-dimethoxybenzene) from guaiacol in Silene latifolia. Veratrole is widely found among plants and is known as a key compound for some plant-insect interactions. In S. latifolia and other Silene species, veratrole is a key compound for pollinator attraction $[5,13,48]$. The related 1, 4-dimethoxybenzene volatile compound has been identified from the flowers of Salix species and this 
Table 1 Substrate specificity of SIGOMT1 and SIGOMT2 with various substrates

\begin{tabular}{lcc}
\hline Substrate & SIGOMT1* (\% Activity) & SIGOMT2 (\% Activity) \\
\hline Guaiacol & 100 & 12 \\
Catechol & 35 & 13 \\
Orcinol & 11 & 9 \\
Eugenol & $<1$ & $<1$ \\
Methyleugenol & $<1$ & $<1$ \\
\hline
\end{tabular}

Purified SIGOMT1 and SIGOMT2 were assayed at room temperature under standard assay conditions by adding substrate at a final concentration of $200 \mu \mathrm{M}$ and excess ${ }^{14} \mathrm{C}$-SAM together. Relative activity is expressed as the percentage of GOMT1 activity with guaiacol as a substrate.

* Specific activity was measured $1.96 \mathrm{NMOL} / \mathrm{MIN} / \mathrm{MG}$ protein at saturating substrate concentrations.

compound serves as an attractant for an oligolectic bee [49]. Schiestl \& Dötterl [50] have also recently shown the evolutionary importance of methoxlated aromatics including veratrole in the association of Araceae plants and their pollinators, but until our study, the molecular basis of veratrole synthesis was unknown in planta.

\section{GOMT and veratrole biosynthesis}

The dioecious Silene latifolia serves as a plant model system for several ecological and evolutionary topics due to its remarkable features including well differentiated heteromorphic sex chromosomes, its nursery pollination system, and the associated floral fragrances [6,7,13,23,51-55]. In S. latifolia, aromatic (e.g., veratrole, phenylacetaldehyde, methylsalicylate, and benzyl benzoate) and montoterpenoid (e. g., lilac aldehydes \& alcohol, $\alpha$-pinene, and linalool) compounds comprise a significant part of the total floral scent emission [6,7]. Genes involved in the synthesis of these few widespread floral volatiles have been characterized in a number of plants, mostly from hermaphroditic species. For instance, genes that are involved in the synthesis of phenylacetaldehyde have been characterized in Petunia [56], Rosa [57], Lycopersicum [58], and Arabidopsis [59]. Similarly, a large number of terpene synthase genes have been isolated and characterized in several plant species [6066]. However, few scent genes have been examined in dioecious species, with one exception being the two terpene synthase genes that are accountable for the synthesis of some sesquiterpenes in Actinia deliciosa flowers [67]. One of these two terpene synthase genes was found to possess conifer diterpene internal sequence (CDIS) domain that is usually characteristic feature of many diterpene synthase and determines their activity $[67,68]$.

Veratrole is a key attractant compound in the floral fragrance of S. latifolia and it is down-regulated, together with other compounds, subsequent to pollination [10]. Our study in this dioecious plant species characterized two candidate "veratrole forming genes", SlGOMT1 and SlGOMT2. Analysis of the activities of the enzymes they encode showed that SIGOMT1 is an efficient and specific guaiacol methyltransferase (Tables 1, 2, and Figures 3-5) whose activity leads to the synthesis of veratrole. SIGOMT1 also had low levels of activity $(<11 \%$ compared with its activity with guaiacol) with several other substrates, with the exception of catechol (Table 2). SIGOMT2, on the other hand, has low levels of activity with guaiacol compared to the activity of SIGOMT1 (Tables 1, 2, and Figure 5), and comparably low levels with several other substrates tested. Therefore, it is not possible to conclude at this point that the presence of SIGOMT2 in the flowers would lead to the synthesis of veratrole, particularly since the $\mathrm{K}_{\mathrm{m}}$ value of SIGOMT2 is relatively high compared with the corresponding value of SlGOMT1 (app. $500 \mu \mathrm{M}$ vs.10 $\mu \mathrm{M}$, Table 2). An examination of the internal concentration of guaiacol in flower tissue is required to resolve this issue.

It has recently been reported that catechol is the substrate of a methyltransferase in tomato fruit (CTOMT) that converts it to guaiacol [47]. Thus, catechol may serve as a precursor of guaiacol in S. latifolia as well. Although SIGOMT1 does show a relatively low level of amino acid similarity to tomato CTOMT, we observed a

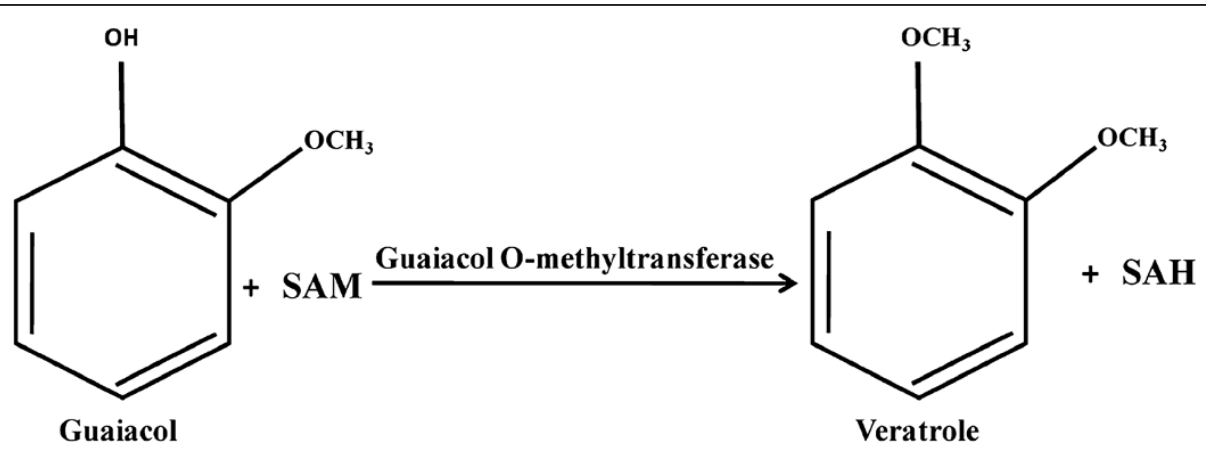

Figure 3 Biosynthesis of veratrole in Silene latifolia. A methyl group from S-adenosyl-L-methionine (SAM) is transferred to the p-hydroxyl group of guaiacol to synthesize veratrole and S-adenosyl-L- homocysteine (SAH). 


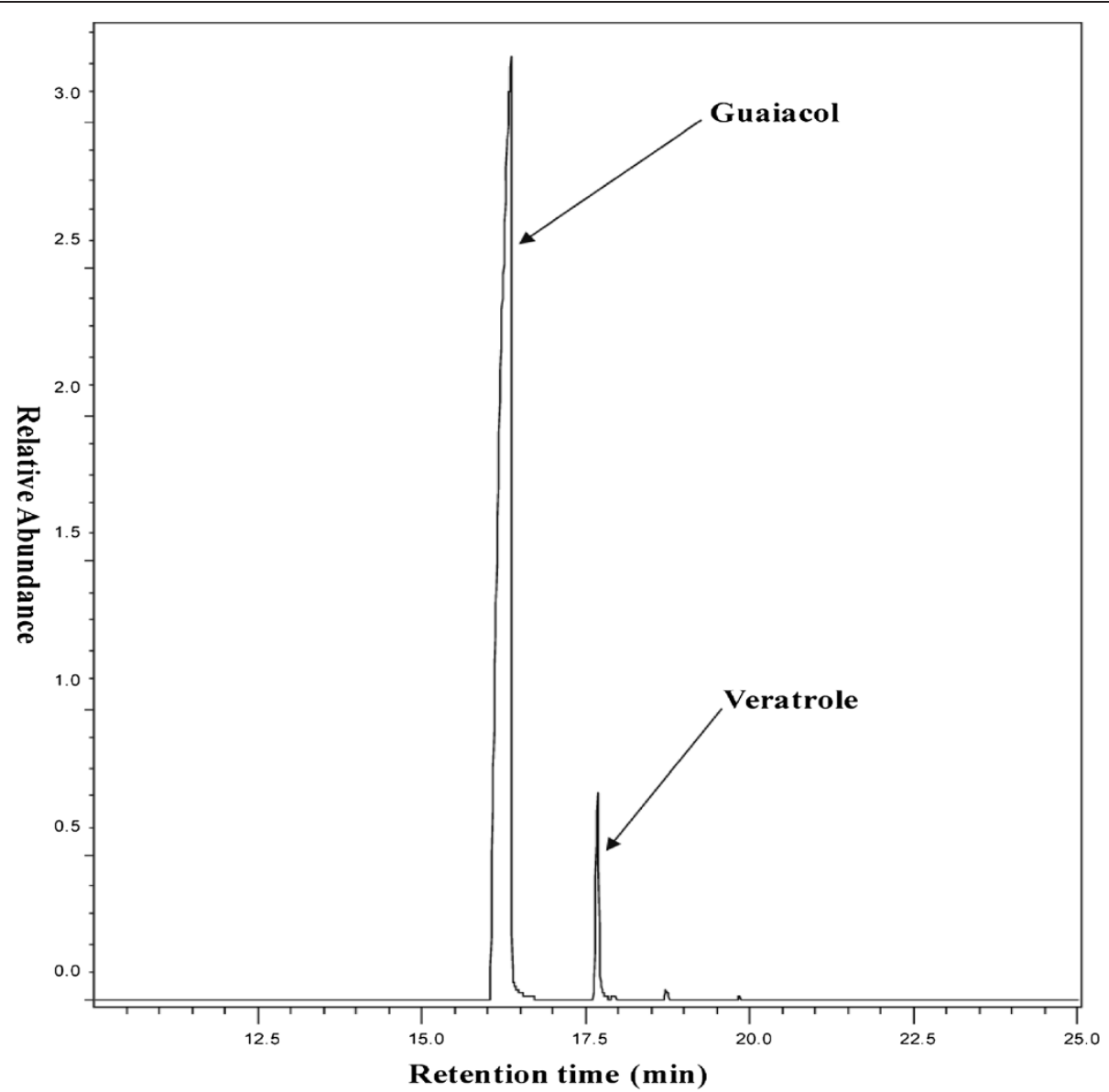

Figure 4 A representative GC chromatogram showing the conversion of guaiacol to veratrole by SIGOMT1. A desalted crude extract from E. coli cells expressing SIGOMT1 was supplied with guaiacol and SAM. Volatile compounds were collected and analyzed as described in methods section.

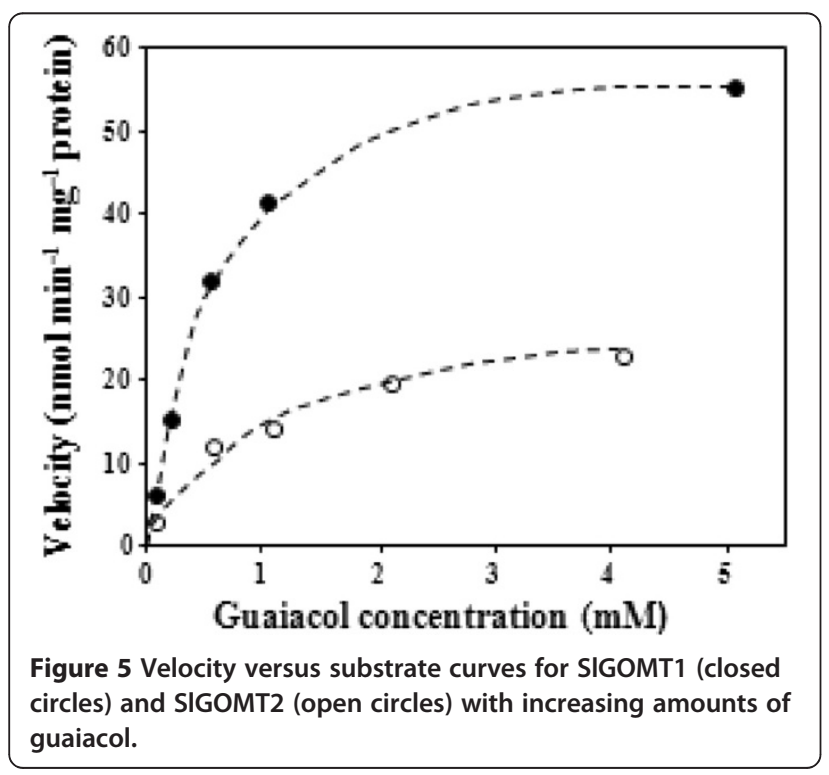

moderate level of activity for SIGOMT1 with catechol (Table 1). While this result is intriguing, additional work such as measuring catechol concentrations in S. latifolia flowers must be carried out to determine whether catechol is indeed the precursor of guaiacol in this system. In tomato, both catechol and guaiacol have been detected in the fruit, but in S. latifolia flowers, only guaiacol emission, but not catechol, have been observed [6,7,10,47].

It is well established that in many species, flower scent emission is governed by a circadian clock and/or light, apparently as an adaption to the temporal activity of their

Table 2 Kinetic parameters of SIGOMT1 and SIGOMT2

\begin{tabular}{|c|c|c|c|}
\hline \multirow{2}{*}{$\begin{array}{l}\text { Recombinant } \\
\text { protein }\end{array}$} & $K_{\mathrm{m}}$ & $K_{\text {cat }}$ & $K_{\text {cat }} / K_{\mathrm{m}}$ \\
\hline & $\mu M$ & $s^{-1}$ & $s^{-1} M^{-1}$ \\
\hline SIGOMT1 & $9.79 \pm 1.51$ & $2.58 \times 10^{-3} \pm 1.64 \times 10^{-4}$ & $270.27 \pm 64.10$ \\
\hline SIGOMT2 & $501 \pm 198$ & $3.95 \times 10^{-3} \pm 1.09 \times 10^{-3}$ & $8.63 \pm 1.81$ \\
\hline
\end{tabular}


Table 3 Veratrole emission and SIGOMT expression in Silene latifolia flowers

\begin{tabular}{|c|c|c|}
\hline Flower / Condition & $\begin{array}{l}\text { Expression } \\
(\text { Mean } \pm \mathrm{SE})\end{array}$ & $\begin{array}{l}\text { Veratrole emission }{ }^{1} \\
(\text { Mean } \pm \text { SE) }\end{array}$ \\
\hline Night flowering ${ }^{2} q$ & $0.31 \pm 0.08$ & $1.36 \pm 0.49$ \\
\hline Day flowering ${ }^{2}$ ㅇ & $0.43 \pm 0.08$ & $0.027 \pm 0.027$ \\
\hline Night flowering ${ }^{2} \widehat{ }$ & $1.11 \pm 0.28$ & $3.86 \pm 3.17$ \\
\hline Day flowering ${ }^{2} \widehat{ }{ }^{\lambda}$ & $1.24 \pm 0.20$ & $0.05 \pm 0.038$ \\
\hline
\end{tabular}

pollinators [37,38,69-71]. Our study and that of Wälti et al. [6] show that scent emission in S. latifolia differs between day and night. Furthermore, SlGOMT expression in male flowers was 3-4 folds higher than in female flowers both during the day and night but this difference was not found for sex-specific veratrole emission. Wälti et al. [7] found significant higher veratrole emission in male compared to female S. latifolia plants and the lack of a significant sex specific difference in our study may be consequence of relatively low sample size combined with high variability in veratrole emission. It is worth noting, however, that Nieuwenhuizen et al. [67] found that $A$. deliciosa female flowers produce more scent than male flowers even though no difference in gene expression was found between flowers of the two sexes.

\section{Evolution of GOMT}

The observation that a single amino difference between SIGOMT1 and SIGOMT2 is responsible for a large difference in catalytic efficiency of veratrole synthesis in S. latifolia is intriguing. Similarly, two duplicated gene copies were characterized for eugenol synthesis in Clarkia breweri in which one copy is about 3.5 fold more efficient than the other [72].

In contrast to $S$. latifolia which emits veratrole in its floral odor, S. dioica emits no veratrole [6]. The two genes found in that species that are closely related to SlGOMTs, SdOMT1, and SdOMT2, were found to be expressed in floral tissue, but, our data show that SdOMT1 and SdOMT2 do not have activity with guaiacol, catechol, or the other substrates tested in this study. It is possible that these enzymes contain mutations that render them inactive. Koeduka et al. [73] found that a single nucleotide substitution in the coding region of the Petunia axillaris subsp parodii isoeugenol synthase (PapIGS) gene has resulted to the loss of the enzymatic activity and thereby, prevents isoeugenol emission from flowers. On the other hand, several studies on the plant OMT family have revealed that one or a few amino acid changes can be responsible for novel substrate specificities, such as in the Clarkia iso(eugenol) OMT [45] and Ocimum phenylpropene-OMTs [74]. Such amino acid changes in
OMT sequences have been found to evolve under positive selection $[75,76]$.

Because the sequences of SlGOMT1 and SlGOMT2 are more similar to each other than to $S d O M T 1$ and SdOMT2 (Figure 6), we do not know if they represent two alleles of the same locus, or a duplication that occurred after the split from S. dioica. The results of the sequence divergence analysis indicate positive selection on SlGOMT1 \& SlGOMT2 (as evidenced by their significant $\mathrm{dN} / \mathrm{dS}$ value, 2.39), suggesting the recent acquisition of GOMT activity in S. latifolia by a few amino acid substitutions. This evolutionary change could be brought about through selection for better discrimination by pollinators from its closely related sister species, $S$. dioica, leading to enhanced floral isolation [77,78]. Alternatively, veratrole could be a key signal in the specific association of $S$. latifolia with its primary pollinator, Hadena bicruris. Pollinatormediated selection is commonly occurring on scent compounds $[79,80]$. Higher amount of veratrole emission can empower higher flower attractiveness from longer distances in S. latifolia [7,13,81]. Although there is no selection detected on $S d O M T$, the evidence for purifying selection before in the branch leading to both SlGOMTs and SdOMTs suggest a conserved role of the ancestral OMT proteins, and it is therefore possible that the SdOMT enzymes have another, as yet uncharacterized functions.

\section{Conclusions}

Two novel flower-specific methyltransferase genes were characterized from $S$. latifolia that are capable of methylating guaiacol and is expressed differentially between male and female individuals. Our study also provides the foundation for future Silene scent molecular research. Altogether, the information provided on genes responsible for scent production and its evolutionary signatures will be relevant for understanding pollinator-driven selection on floral scent variation in plants.

\section{Methods}

\section{Plant materials}

S. latifolia and S. dioica plants were grown under green house conditions at the Hönggerberg and Eschikon experimental sites of ETH Zurich. Flowers were harvested after dusk (mid night). The flowers were snap-frozen in liquid nitrogen after collection and stored at $-80^{\circ} \mathrm{C}$ until use. Total RNAs were extracted from flowers using the RNeasy plant mini kit (Qiagen) and poly A + mRNA was isolated using the Oligotex mRNA kit (Qiagen) according to the manufacturer's instructions. 


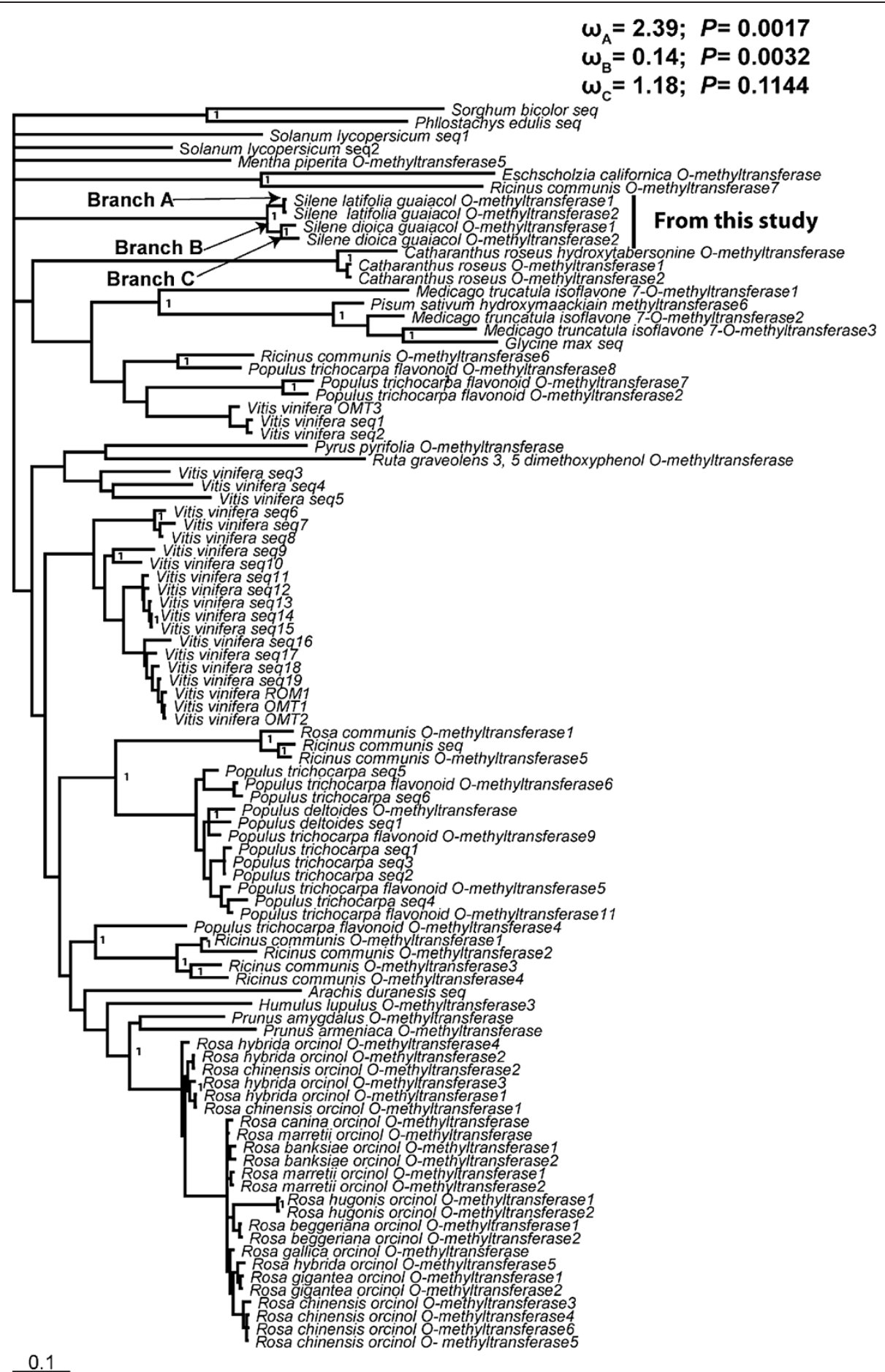

Figure 6 Phylogenetic analysis of Silene GOMT homologs. Bayesian phylogeny with branch length from BaseML is shown and numbers indicate posterior probabilities (only 1.0 value mentioned) next to branches.

Isolation of full-length SIGOMTs \& SdOMTs

S. latifolia floral EST libraries were searched against sequences with homology to known members of plant methyltransferase families using the BLASTX algorithm
[82]. One partial sequence showing similarity with rose orcinol O-methyltransferase was selected for isolation of the full-length cDNA sequence. Complete coding cDNA sequences were isolated using the SMART-RACE cDNA 
amplification kit (Clontech) according to the manufacturer's protocol. Gene-specific primer pairs were used to obtain the full-length cDNA sequence from S. latofolia as well as from $S$. dioica, and the resulting PCR products were cloned into the pSMART vector (Lucigen). Inserts were verified by sequencing. Two coding sequences each from S. latifolia and S. dioica were isolated.

\section{Preparation of Silene GOMT constructs}

To determine whether SlGOMT1, SlGOMT2, SdOMT1, and $S d O M T 2$ potentially encode functional proteins, we amplified the complete open reading frames including start codons but without native stop codons at the end. The protein coding regions (ORFs) of SlGOMTs and SdOMTs were amplified by RT-PCR using an upstream primer and a downstream primer (Additional file 4: Table S3). PCR amplification was carried out for 30 cycles after an initial denaturation at $94^{\circ} \mathrm{C}$ for $2 \mathrm{~min}$. Each cycle consisted of denaturation at $94^{\circ} \mathrm{C}$ for $1 \mathrm{~min}$, annealing at $55^{\circ} \mathrm{C}$ for $1 \mathrm{~min}$ and extension at $72^{\circ} \mathrm{C}$ for 2 min with a final extension of $7 \mathrm{~min}$ in a Biometra thermocycler. The resulting PCR products were cloned into expression vector using $\mathrm{pEXP}-\mathrm{CT} / \mathrm{Topo} \mathrm{TA}$ expression kit according to manufacturer's instructions. The constructs were subjected to complete sequencing to confirm the orientation of the inserts.

\section{GOMT activity, purification, enzymatic assays, and product identification}

SlGOMT1, SlGOMT2, SdOMT1, and SdOMT2 constructs were transformed into E. coli BL21-CodonPlus (DE3)RIPL cells (Stratagene). Cells harboring constructs were cultured in LB medium until an $\mathrm{OD}_{600}$ of 0.6. Isopropyl 1-thio- $\beta$-D-galactopyranoside (IPTG) was added to a final concentration of $1 \mathrm{mM}$ to induce protein expression and cells were incubated for 16 hours at $18^{\circ} \mathrm{C}$. Cell pellets resuspended in Buffer A $(100 \mathrm{mM}$ Tris $-\mathrm{HCl}$, $5 \mathrm{mM} \mathrm{MgCl}_{2}, 10 \mathrm{mM} \beta$-mercaptoethanol, $10 \%$ glycerol [v/v], pH 7.5) were subsequently ruptured by sonication. Clarified crude extracts were desalted on PD-10 columns equilibrated with Buffer $\mathrm{A}$ and protein concentration was estimated with the standard Bradford method. Enzymatic activity was performed essentially as described by Wang et al. [83]. Enzyme (10-20 $\mu$ g of desalted crude extract) was incubated in a final volume of $50 \mu \mathrm{l}$ with $0.2 \mathrm{mM}$ substrate (guaiacol, orcinol, catechol, eugenol, and methyleugenol) and $5 \mu \mathrm{M} \mathrm{S}$-[methyl- $\left.{ }^{14} \mathrm{C}\right]$ adenosylL-Met $(40-60 \mathrm{mCi} / \mathrm{mmol})$ for 30 minutes at room temperature. Reaction products were extracted with $200 \mu \mathrm{l}$ of ethyl acetate and $100 \mu \mathrm{L}$ of the organic phase was transferred to $2 \mathrm{ml}$ of non-aqueous scintillation fluid and subjected to a scintillation counter (model 2S6800, Beckman). Approximately $50 \mu \mathrm{g}$ of desalted crude extract was incubated in a final volume of $200 \mu \mathrm{l}$ containing $1 \mathrm{mM}$ guaiacol and $1 \mathrm{mM}$ SAM in buffer $\mathrm{A}$ for 30 minutes at room temperature and SPME device was employed for volatile collection.

The recombinant SIGOMT1 and SIGOMT2 proteins produced in $E$. coli were purified by $\mathrm{Ni}^{2+}$ affinity chromatography (Qiagen), according to the manufacturer's instructions. Briefly, crude protein extracts were desalted into Buffer B (100 mM potassium phosphate, $150 \mathrm{mM}$ $\mathrm{NaCl}, 10 \mathrm{mM}$ imidazole, $\mathrm{pH} 7.5$ ) and applied to $0.5 \mathrm{~mL}$ of $\mathrm{Ni}^{2+}$ resin. Following 10 column washes with Buffer $\mathrm{B}$, proteins bound to the resin were eluted with Buffer B containing $250 \mathrm{mM}$ imidazole. Eluted proteins were desalted into Buffer A and concentrated using Amicon ultra-15 filters (Millipore). Protein purity of the eluted proteins was assessed by SDS-PAGE and concentration was determined as described above. For kinetic analysis, assays were performed as described above with $\sim 0.5 \mu \mathrm{g}$ of purified SIGOMT1 or 2 and various concentrations of guaiacol, while SAM concentration was held constant at $200 \mu \mathrm{M}$. Reactions were stopped by the addition of $10 \mu \mathrm{L}$ of 2 N HCL. Double reciprocal plots were used to determine the apparent $K_{m}$ and $V_{\text {max }}$ for each enzyme.

\section{Scent collection}

Floral odor was collected in a climate chamber using the dynamic heaspace method. We collected odor at light from $4 \mathrm{AM}$ to $8 \mathrm{PM}$ and in the dark from $9 \mathrm{PM}$ to 3 AM. Five individuals each of both sexes were used for floral volatile collection and three individuals of each sex were selected for leaf volatile collection. Intact newly opened whole flowers and new leaves of these individuals were enclosed in an oven roasting bag (Nalophan ${ }^{\circledR}$ ) and air was sucked out from these bags using a battery operated pump (PAS-500 Personal Air Sampler, Spectrey, Redwood city, California, USA). Volatiles were trapped in self made absorbent glass tubes filled with Tenax for 30 min during day and night. Control samples were also collected for discriminating the compounds from surrounding air contaminations and their average was subtracted from the each sample. All glass filters were capped with teflon tape on both sides and enclosed in the aluminium foil to avoid contamination, and samples were preserved for subsequent gas chromatograph (GC) analysis at $-20^{\circ} \mathrm{C}$.

\section{Quantitative gas chromatographic analysis and compound identification}

Volatile samples were analyzed within 4 days of volatile collections by a gas chromatograph (GC, Agilent $6890 \mathrm{~N})$ connected to an HP5 column $(30 \mathrm{~m} \times 0.32 \mathrm{~mm}$ internal diameter $\times 0.25 \mu \mathrm{m}$ film thickness) and an Agilent 5975 mass selective detector associated to a thermal desorption system (TDS2, Gerstel, Mühlheim Germany). The TDS temperature was adjusted to rise from 
$30^{\circ}$ (0.5-min hold) to $240^{\circ} \mathrm{C}\left(1\right.$-min hold) at $60^{\circ} \mathrm{C}$ per minute. The CIS (cold injection system) temperature was set to rise from $-50^{\circ} \mathrm{C}(0.5$-min hold $)$ to $150^{\circ} \mathrm{C}(0.5-\mathrm{min}$ hold) at $16^{\circ} \mathrm{C}$ per second and to $250^{\circ} \mathrm{C}(0.5$-min hold $)$ at $12^{\circ} \mathrm{C}$ per second. The oven temperature of the GC6890 was programmed to rise from $50^{\circ} \mathrm{C}$ (3 min hold) to $230^{\circ} \mathrm{C}$ at $8^{\circ} \mathrm{C}$ per minute. Agilent ChemStation and MSD ChemStation E.02.00.493 (Agilent Technologies, Palo Alto, California, USA) software were utilized for characterizing the peaks and retention times. Synthetic veratrole (Sigma-Aldrich, Switzerland) was further employed as a standard for comparing the retention time as well as calibrating peak area with absolute amount in the mass spectrometry chromatograms. Quantified amount of veratrole was estimated in ng per liter of air sampled.

\section{Real time RT-PCR analysis}

We used the same set of flower and leaf samples for gene expression analysis that were also used for volatile collections. After each volatile collection, floral and leaf tissues were immediately harvested and snap-frozen in liquid nitrogen. All these samples were stored at $-80^{\circ} \mathrm{C}$ until required. Total RNA was extracted from flowers and leaf using the RNeasy plant mini kit (Qiagen). RNA was subsequently subjected to DNAse treatment using RQ1 RNase-Free DNase (Promega, Madison, Wisconsin, USA) following manufacturer's instructions. First-strand cDNA was synthesized by M-MLV Reverse Transcriptase (Promega, Madison, Wisconsin, USA) and an Oligo (dT $)_{15}$ primer. As a control for possible DNA contamination, reverse transcriptions were done with and without the enzyme. RT-PCRs were performed with the SYBR Master Mix (Applied Biosystems, Foster City, USA) on a 7500 Real Time PCR System (Applied Biosystems, Foster City, USA). Actin, EF1A, and CL285 primers were applied as internal controls and qRT-GOMT primers were used for amplification (Additional file 4: Table S3). All samples including control reactions were performed three times. The results were recorded by 7500 Software v 2.0.1 (Applied Biosystems, Foster City, USA). At least three sets of independent experiments were performed to calculate a mean cycle threshold $(\mathrm{Ct})$ value and standard deviations.

\section{Statistical analysis}

Non-parametric Mann Whitney U-tests were used to analyze the differences in veratrole emission and gene expression between sexes and day/night. All analyses were performed using SPSS statistical package (SPSS Inc. Chicago).

\section{Phylogeny reconstruction and selection analysis}

SlGOMT1 sequence was chosen as a seed for retrieval of homologous sequences from NCBI using BlastN searches and combined with the sequences that were generated from this study. BlastN searches were optimized using 'somewhat similar sequences' option following general parameters (Max target sequences 100, expect threshold 10, word size 11 , and match/mismatch scores 2,-3). DNA sequences were aligned with BioEdit v7.0.5 and poorly aligned 8 sequences from the pool of selected 100 sequences were excluded for subsequent analysis. The best substitution model was estimated using Mr. Modeltest 2.3 [84]. The Markov Chain Monte Carlo (MCMC) method was employed to approximate the posterior probabilities of trees using MrBayes 3.1.2 [85]. Branch lengths of obtained consensus tree were optimized with BaseML. CodeML was further used for a codon-based model. Both programs belong to PAML 4.4 package [86].

\section{Additional files}

Additional file 1: Figure S4. Comparison of mass spectra of veratrole. Additional file 2: Table S1. Sequences used for phylogenetic analysis. Additional file 3: Table S2. Analysis of selection using PAML.

Additional file 4: Table S3. Primers used in this study.

\section{Competing interest}

The authors declare that they have no competing interest.

\section{Authors' contributions}

AKG, FPS, and EP conceived the project. AKG carried out experiments, analyses, and wrote the manuscript. TA contributed to SIGOMTs biochemical assays \& protein purification. FPS, EP, and AW assisted in experiment design and contributed to manuscript preparation. All authors read the manuscript and approved it.

\section{Acknowledgments}

The authors would like to thank Claudia Michel and Niklaus Zemp for their help in the qRT-PCR experiment. We also wish to thank Dr. Aria Minder for kindly sharing S. latifolia reference primers for the GRT-PCR experiment, Dr. Edward Connor for his assistance in volatile collections and GC-MS analysis, Dr. Philipp Schlüter for his help in evolutionary analysis, and the Genetic Diversity Centre (GDC) of ETH Zurich for providing the facility to perform qRT-PCR experiments. This research was supported by the Swiss National Science Foundation grant to FPS (SNF; project No. 31003A-112342) and ETH Zürich doctoral scholarship to AKG.

\section{Author details}

'Institute of Systematic Botany, University of Zurich, Zurich CH-8008, Switzerland. ${ }^{2}$ ETH Zurich, Institute of Integrative Biology, Plant Ecological Genetics, Zurich CH-8092, Switzerland. ${ }^{3}$ Department of Molecular, Cellular and Developmental Biology, University of Michigan, Ann Arbor, MI, USA.

Received: 24 April 2012 Accepted: 27 August 2012

Published: 31 August 2012

\section{References}

1. Brantjes N: Sensory responses to flowers in night-flying moths. London: academic press; 1978:13-19.

2. Shykoff J, Bucheli E: Pollinator visitation patterns, floral rewards and the probability of transmission of Microbotryum violaceum, a venereal disease of plants. J Ecol 1995, 83:189-198.

3. Jürgens A, Witt T, Gottberger G: Reproduction and pollination in central european populations of Silene and Saponaria species. Bot Acta 1996, 109:316-324. 
4. Dötterl S, Jurgens A: Spatial fragrance patterns in flowers of Silene latifolia: Lilac compounds as olfactory nectar guides? Plant Syst Evol 2005, 255:99-109

5. Jürgens $A$, Witt T, Gottsberger G: Flower scent composition in nightflowering Silene species (Caryophyllaceae). Biochem Syst Ecol 2002, 30:383-397.

6. Wälti M, Muhlemann J, Widmer A, Schiestl F: Floral odour and reproductive isolation in two species of Silene. J Evol Biol 2008, 21:111-121.

7. Wälti M, Page P, Widmer A, Schiestl F: How to be an attractive male: floral dimorphism and attractiveness to pollinators in a dioecious plant. BMC Evol Biol 2009, 9:190.

8. Brantjes N: Riddles around pollination of Melandrium album (Mill) Garcke (Caryophyllaceae) during oviposition by Hadena bicruris Hufn (Noctuidae, Lepidoptera) .2. Proceedings of the Koninklijke Nederlandse Akademie Van Wetenschappen Series C-Biological and Medical Sciences 1976, 79:127-141

9. Kephart S, Reynolds R, Rutter M, Fenster C, Dudash M: Pollination and seed predation by moths on Silene and allied Caryophyllaceae: evaluating a model system to study the evolution of mutualisms. New Phytol 2006, 169:667-680.

10. Mühlemann J, Wälti M, Widmer A, Schiestl F: Postpollination changes in floral odor in Silene latifolia adaptive mechanisms for seed-predator avoidance? J Chem Ecol 2006, 32:1855-1860.

11. Bopp S, Gottsberger G: Importance of Silene latifolia ssp. alba and S. dioica (Caryophyllaceae) as host plants of the parasitic pollinator Hadena bicruris (Lepidoptera, Noctuidae). Oikos 2004, 105:221-228.

12. Wolfe LM: Why alien invaders succeed: support for the escape-fromenemy hypothesis. Am Nat 2002, 160:705-711.

13. Dötterl S, Jürgens A, Seifert K, Laube T, Weissbecker B, Schutz S: Nursery pollination by a moth in Silene latifolia : the role of odours in eliciting antennal and behavioural responses. New Phytol 2006, 169:707-718.

14. Dötterl S, Burkhardt D, Jürgens A, Mosandl A: Stereoisomeric pattern of lilac aldehyde in Silene latifolia, a plant involved in a nursery pollination system. Phytochemistry 2007, 68:499-504.

15. Jürgens A: Flower scent composition in diurnal Silene species (Caryophyllaceae): phylogenetic constraints or adaption to flower visitors? Biochem Syst Ecol 2004, 32:841-859.

16. Scutt C, Li Y, Robertson S, Willis M, Gilmartin P: Sex determination in dioecious Silene latifolia - Effects of the $Y$ chromosome and the parasitic smut fungus (Ustilago violacea) on gene expression during flower development. Plant Physiol 1997, 114:969-979.

17. Charlesworth D: Plant sex determination and sex chromosomes. Heredity 2002, 88:94-101.

18. Qiu S, Bergero R, Forrest A, Kaiser VB, Charlesworth D: Nucleotide diversity in Silene latifolia autosomal and sex-linked genes. Proc R Soc B Biol Sci 2010, 277:3283-3290.

19. Bergero R, Charlesworth D: Preservation of the $Y$ transcriptome in a 10million-year-old plant sex chromosome system. Curr Biol 2011, 21:1470-1474.

20. Vyskot B, Araya A, Veuskens J, Negrutiu I, Mouras A: DNA methylation of sex chromosomes in a dioecious plant, Melandrium album. Mol Gen Genet 1993, 239:219-224.

21. Zluvova J, Georgiev S, Janousek B, Charlesworth D, Vyskot B, Negrutiu L: Early events in the evolution of the Silene latifolia $Y$ chromosome: male specialization and recombination arrest. Genetics 2007, 177:375-386.

22. Marais G, Nicolas M, Bergero R, Chambrier P, Kejnovsky E, Moneger F, Hobza R, Widmer A, Charlesworth D: Evidence for degeneration of the $Y$ chromosome in the dioecious plant Silene latifolia. Curr Biol 2008, 18:545-549.

23. Mrackova M, Nicolas M, Hobza R, Negrutiu I, Moneger F, Widmer A: Independent origin of sex chromosomes in two species of the genus Silene. Genetics 2008, 179:1129-1133.

24. Chibalina MV, Filatov DA: Plant Y chromosome degeneration is retarded by haploid purifying selection. Curr Biol 2011, 21:1475-1479.

25. Minder A, Rothenbuehler C, Widmer A: Genetic structure of hybrid zones between Silene latifolia and Silene dioica (Caryophyllaceae): evidence for introgressive hybridization. Mol Ecol 2007, 16:2504-2516.

26. Minder AM, Widmer A: A population genomic analysis of species boundaries: neutral processes, adaptive divergence and introgression between two hybridizing plant species. Mol Ecol 2008, 17:1552-1563.

27. Moccia M, Oger-Desfeux C, Marais G, Widmer A: A White Campion (Silene latifolia) floral expressed sequence tag (EST) library: annotation, EST-SSR characterization, transferability, and utility for comparative mapping. BMC Genomics 2009, 10(1):243.

28. Blavet N, Charif D, Oger-Desfeux C, Marais G, Widmer A: Comparative high-throughput transcriptome sequencing and development of SiESTa, the Silene EST annotation database. BMC Genomics 2011, 12:376.

29. Ibrahim RK, Bruneau A, Bantignies B: Plant O-methyltransferases: molecular analysis, common signature and classification. Plant Mol Bio/ 1998, 36:1-10.

30. Gowri G, Bugos RC, Campbell WH, Maxwell CA, Dixon RA: Stress responses in alfalfa (Medicago sativa L.): X. molecular cloning and expression of S-adenosylL-methionine:caffeic acid 3-O-methyltransferase, a key enzyme of lignin biosynthesis. Plant Physiol 1991, 97:7-14.

31. Ye ZH, Varner JE: Differential expression of two O-methyltransferases in lignin biosynthesis in Zinnia elegans. Plant Physiol 1995, 108:459-467.

32. Hugueney P, Provenzano S, Verriès C, Ferrandino A, Meudec E, Batelli G, Merdinoglu D, Cheynier V, Schubert A, Ageorges A: A novel cationdependent $O$-methyltransferase involved in anthocyanin methylation in grapevine. Plant Physiol 2009, 150:2057-2070.

33. Fournier-Level A, Hugueney $P$, Verriès $C$, This $P$, Ageorges A: Genetic mechanisms underlying the methylation level of anthocyanins in grape (Vitis vinifera L.). BMC Plant Biol 2011, 11:179.

34. He X-Z, Dixon RA: Genetic manipulation of isoflavone 7-Omethyltransferase enhances biosynthesis of 4'-O-methylated isoflavonoid phytoalexins and disease resistance in alfalfa. Plant Cell 2000, 12:1689-1702.

35. Schmidlin L, Poutaraud A, Claudel P, Mestre P, Prado E, Santos-Rosa M, Wiedemann-Merdinoglu S, Karst F, Merdinoglu D, Hugueney P: A stressinducible resveratrol O-methyltransferase involved in the biosynthesis of pterostilbene in grapevine. Plant Physiol 2008, 148:1630-1639.

36. Schmitt $D$, Pakusch $A E$, Matern $U$ : Molecular cloning, induction and taxonomic distribution of caffeoyl-CoA 3-O-methyltransferase, an enzyme involved in disease resistance. J Biol Chem 1991, 266:17416-17423.

37. Dudareva N, Murfitt LM, Mann CJ, Gorenstein N, Kolosova N, Kish CM, Bonham C, Wood K: Developmental regulation of methyl benzoate biosynthesis and emission in snapdragon flowers. Plant Cell 2000, 12:949-961.

38. Kolosova N, Sherman D, Karlson D, Dudareva N: Cellular and subcellular localization of S-adenosyl-I-methionine:benzoic acid carboxyl methyltransferase, the enzyme responsible for biosynthesis of the volatile ester methylbenzoate in snapdragon flowers. Plant Physiol 2001, 126:956-964.

39. Wu S, Watanabe N, Mita S, Dohra H, Ueda Y, Shibuya M, Ebizuka Y: The key role of phloroglucinol O-methyltransferase in the biosynthesis of Rosa chinensis volatile 1,3,5-trimethoxybenzene. Plant Physiol 2004, 135:95-102.

40. Tieman D, Zeigler M, Schmelz E, Taylor MG, Rushing S, Jones JB, Klee HJ: Functional analysis of a tomato salicylic acid methyl transferase and its role in synthesis of the flavor volatile methyl salicylate. Plant J 2010, 62:113-123.

41. Lewinsohn E, Ziv-Raz I, Dudai N, Tadmor Y, Lastochkin E, Larkov O, Chaimovitsh D, Ravid U, Putievsky E, Pichersky E, Shoham Y: Biosynthesis of estragole and methyl-eugenol in sweet basil (Ocimum basilicum L). Developmental and chemotypic association of allylphenol Omethyltransferase activities. Plant Sci 2000, 160:27-35

42. Gang DR, Lavid N, Zubieta C, Chen F, Beuerle T, Lewinsohn E, Noel JP, Pichersky E: Characterization of phenylpropene O-methyltransferases from sweet basil: facile change of substrate specificity and convergent evolution within a plant O-methyltransferase family. Plant Cell 2002, 14:505-519.

43. Scalliet $G$, Lionnet $C$, Le Bechec M, Dutron L, Magnard J-L, Baudino S, Bergougnoux V, Jullien F, Chambrier P, Vergne P, et al: Role of petal-specific orcinol O-methyltransferases in the evolution of rose scent. Plant Physiol 2006, 140:18-29.

44. Scalliet G, Piola F, Douady CJ, Réty S, Raymond O, Baudino S, Bordji K, Bendahmane M, Dumas C, Cock JM, Hugueney P: Scent evolution in Chinese roses. Proc Natl Acad Sci 2008, 105:5927-5932.

45. Wang J, Pichersky E: Identification of specific residues involved in substrate discrimination in two plant O-methyltransferases. Arch Biochem Biophys 1999, 368:172-180.

46. Dunlevy J, Soole K, Perkins M, Dennis E, Keyzers R, Kalua C, Boss P: Two O-methyltransferases involved in the biosynthesis of methoxypyrazines: grape-derived aroma compounds important to wine flavour. Plant Mol Biol 2010, 74:77-89. 
47. Mageroy MH, Tieman DM, Floystad A, Taylor MG, Klee HJ: A Solanum lycopersicum catechol-O-methyltransferase involved in synthesis of the flavor molecule guaiacol. Plant J 2012, 69:1043-1051.

48. Jhumur US, Dötterl S, Jürgens A: Naïve and conditioned responses of Culex pipiens pipiens biotype molestus (Diptera: Culicidae) to flower odors. J Med Entomol 2006, 43:1164-1170.

49. Dötterl S, Füssel U, Jürgens A, Aas G: 1,4-dimethoxybenzene, a floral scent compound in willows that attracts an oligolectic bee. J Chem Ecol 2005, 31:2993-2998

50. Schiestl FP, Dötterl S: The evolution of floral scent and olfactory preferences in pollinators: coevolution or pre-existing bias? Evolution 2012, 66(7):2042-2055.

51. Bernasconi G, Antonovics J, Biere A, Charlesworth D, Delph L, Filatov D, Giraud T, Hood M, Marais G, McCauley D, et al: Silene as a model system in ecology and evolution. Heredity 2009, 103:5-14

52. Labouche A-M, Bernasconi G: Male moths provide pollination benefits in the Silene latifolia-Hadena bicruris nursery pollination system. Funct Ecol 2010, 24:534-544.

53. Biere A, Honders SC: Coping with third parties in a nursery pollination mutualism: Hadena bicruris avoids oviposition on pathogen-infected, less rewarding Silene latifolia. New Phytol 2006, 169:719-727.

54. Dötterl $S$, Wolfe $L$, Jürgens A: Qualitative and quantitative analyses of flower scent in Silene latifolia. Phytochemistry 2005, 66:203-213.

55. Miller P, Kesseli R: A sex-chromosome mutation in Silene latifolia. Sex Plant Reprod 2011, 24:211-217

56. Kaminaga Y, Schnepp J, Peel G, Kish CM, Ben-Nissan G, Weiss D, Orlova I, Lavie O, Rhodes D, Wood K, et al: Plant phenylacetaldehyde synthase is a bifunctional homotetrameric enzyme that catalyzes phenylalanine decarboxylation and oxidation. J Biol Chem 2006, 281:23357-23366.

57. Farhi M, Lavie O, Masci T, Hendel-Rahmanim K, Weiss D, Abeliovich H, Vainstein A: Identification of rose phenylacetaldehyde synthase by functional complementation in yeast. Plant Mol Biol 2010, 72:235-245

58. Tieman D, Taylor M, Schauer N, Fernie AR, Hanson AD, Klee HJ: Tomato aromatic amino acid decarboxylases participate in synthesis of the flavor volatiles 2-phenylethanol and 2-phenylacetaldehyde. Proc Natl Acad Sci 2006, 103:8287-8292.

59. Gutensohn M, Klempien A, Kaminaga Y, Nagegowda DA, Negre-Zakharov F, Huh J-H, Luo H, Weizbauer R, Mengiste T, Tholl D, Dudareva N: Role of aromatic aldehyde synthase in wounding/herbivory response and flower scent production in different Arabidopsis ecotypes. Plant J 2011, 66:591-602.

60. Phillips MA, Wildung MR, Williams DC, Hyatt DC, Croteau R: cDNA isolation, functional expression, and characterization of (+)-a-pinene synthase and (-)-a-pinene synthase from loblolly pine (Pinus taeda): Stereocontrol in pinene biosynthesis. Arch Biochem Biophys 2003, 411:267-276.

61. Tholl D, Chen F, Petri J, Gershenzon J, Pichersky E: Two sesquiterpene synthases are responsible for the complex mixture of sesquiterpenes emitted from Arabidopsis flowers. Plant J 2005, 42:757-771.

62. Nagegowda DA, Gutensohn M, Wilkerson CG, Dudareva N: Two nearly identical terpene synthases catalyze the formation of nerolidol and linalool in snapdragon flowers. Plant J 2008, 55:224-239.

63. Dudareva N, Martin D, Kish CM, Kolosova N, Gorenstein N, Fäldt J, Miller B, Bohlmann J: (E)- $\beta$-Ocimene and myrcene synthase genes of floral scent biosynthesis in snapdragon: function and expression of three terpene synthase genes of a new terpene synthase subfamily. Plant Cell 2003, 15:1227-1241.

64. Bohlmann J, Steele CL, Croteau R: Monoterpene synthases from grand fir (Abies grandis). cDNA isolation, characterization, and functional expression of myrcene synthase, (-)-(4S)-limonene synthase, and (-)-(1S,5S)-pinene synthase. J Biol Chem 1997, 272:21784-21792.

65. Bohlmann J, Phillips M, Ramachandiran V, Katoh S, Croteau R: cDNA cloning, characterization, and functional expression of four new monoterpene synthase members of the Tpsd gene family from grand fir (Abies grandis). Arch Biochem Biophys 1999, 368:232-243.

66. Falara V, Akhtar TA, Nguyen TTH, Spyropoulou EA, Bleeker PM, Schauvinhold I, Matsuba Y, Bonini ME, Schilmiller AL, Last RL, et al: The tomato terpene synthase gene family. Plant Physiol 2011, 157:770-789.

67. Nieuwenhuizen NJ, Wang MY, Matich AJ, Green SA, Chen X, Yauk Y-K, Beuning LL, Nagegowda DA, Dudareva N, Atkinson RG: Two terpene synthases are responsible for the major sesquiterpenes emitted from the flowers of kiwifruit (Actinidia deliciosa). J Exp Bot 2009, 60:3203-3219.
68. Bohlmann J, Meyer-Gauen G, Croteau R: Plant terpenoid synthases: Molecular biology and phylogenetic analysis. Proc Natl Acad Sci 1998, 95:4126-4133.

69. Jakobsen HB, Olsen CE: Influence of climatic factors on emission of flower volatiles in situ. Planta 1994, 192:365-371.

70. Helsper JPFG, Davies JA, Bouwmeester HJ, Krol AF, van Kampen MH: Circadian rhythmicity in emission of volatile compounds by flowers of Rosa hybrida L. cv. honesty. Planta 1998, 207:88-95.

71. Schiestl FP, Ayasse M, Paulus HF, Erdmann D, Francke W: Variation of floral scent emission and postpollination changes in individual flowers of Ophrys sphegodes Subsp. sphegodes. J Chem Ecol 1997, 23:2881-2895.

72. Koeduka T, Louie GV, Orlova I, Kish CM, Ibdah M, Wilkerson CG, Bowman ME, Baiga TJ, Noel JP, Dudareva N, Pichersky E: The multiple phenylpropene synthases in both Clarkia breweri and Petunia hybrida represent two distinct protein lineages. Plant J 2008, 54:362-374.

73. Koeduka T, Orlova I, Baiga TJ, Noel JP, Dudareva N, Pichersky E: The lack of floral synthesis and emission of isoeugenol in Petunia axillaris subsp. parodii is due to a mutation in the isoeugenol synthase gene. Plant $J$ 2009, 58:961-969.

74. Gang DR, Wang J, Dudareva N, Nam KH, Simon JE, Lewinsohn E, Pichersky $E$ : An investigation of the storage and biosynthesis of phenylpropenes in sweet basil. Plant Physiol 2001, 125:539-555.

75. Barkman TJ: Evidence for positive selection on the floral scent gene isoeugenol-O-methyltransferase. Mol Biol Evol 2003, 20:168-172.

76. Barkman TJ, Martins TR, Sutton E, Stout JT: Positive selection for single amino acid change promotes substrate discrimination of a plant volatileproducing enzyme. Mol Biol Evol 2007, 24:1320-1329.

77. Marais GAB, Forrest A, Kamau E, Käfer J, Daubin V, Charlesworth D: Multiple nuclear gene phylogenetic analysis of the evolution of dioecy and sex chromosomes in the genus Silene. PLoS One 2011, 6:e21915.

78. Markova M, Michu E, Vyskot B, Janousek B, Zluvova J: An interspecific hybrid as a tool to study phylogenetic relationships in plants using the GISH technique. Chromosome Res 2007, 15:1051-1059.

79. Schiestl FP: The evolution of floral scent and insect chemical communication. Ecol Lett 2010, 13:643-656.

80. Galen C: Measuring pollinator-mediated selection on morphometric floral traits: bumblebees and the alpine skypilot, Polemonium viscosum. Evolution 1989, 43:882-890.

81. Schiestl F, Huber F, Gomez J: Phenotypic selection on floral scent: tradeoff between attraction and deterrence? Evol Ecol 2011 25:237-248.

82. Altschul S, Gish W, Miller W, Myers E, Lipman D: Basic local alignment search tool. J Mol Biol 1990, 215:403-410.

83. Wang J, Dudareva N, Bhakta S, Raguso RA, Pichersky E: Floral scent production in Clarkia breweri (Onagraceae): II. Localization and developmental modulation of the enzyme S-adenosyl-L-methionine:(Iso) eugenol O-methyltransferase and phenylpropanoid emission. Plant Physiol 1997, 114:213-221.

84. Nylander J: MrModeltest v2. Program distributed by the author Evolutionary Biology Centre: Uppsala University; 2004.

85. Ronquist F, Huelsenbeck J: MrBayes 3: Bayesian phylogenetic inference under mixed models. Bioinformatics 2003, 19:1572-1574.

86. Yang Z: PAML 4: phylogenetic analysis by maximum likelihood. Mol Biol Evol 2007, 24:1586-1591.

doi:10.1186/1471-2229-12-158

Cite this article as: Gupta et al:: Identification of white campion (Silene latifolia) guaiacol $\mathrm{O}$-methyltransferase involved in the biosynthesis of veratrole, a key volatile for pollinator attraction. BMC Plant Biology 2012 12:158. 